\title{
Case Report \\ Renal Cell Carcinoma Metastasis to the Breast: A Rare Presentation
}

\author{
Heba O. E. Ali $\mathbb{D}^{1},{ }^{1}$ Tamer Ghorab ${ }^{D},{ }^{1}$ Iain R. Cameron ${ }^{(D)},{ }^{1}$ and Ahmed M. S. M. Marzouk $(\mathbb{D})^{1,2}$ \\ ${ }^{1}$ Altnagelvin Area Hospital, WHSC Trust, UK \\ ${ }^{2}$ Faculty of Medicine, Cairo University, Egypt \\ Correspondence should be addressed to Heba O. E. Ali; hebaosama@live.com
}

Received 1 December 2020; Accepted 21 April 2021; Published 7 May 2021

Academic Editor: Roberto Iezzi

Copyright (C) 2021 Heba O. E. Ali et al. This is an open access article distributed under the Creative Commons Attribution License, which permits unrestricted use, distribution, and reproduction in any medium, provided the original work is properly cited.

\begin{abstract}
Worldwide breast malignancy is the most common cancer in women; however, metastases to the breast from extramammary malignancies are very rare and only a few sporadic cases are reported in the international literature. In this article, the authors report a case of a 73-year-old woman, who underwent nephrectomy for clear cell renal cell carcinoma and 3 years later presented with a breast metastasis from renal cell carcinoma (clear cell type).
\end{abstract}

\section{Introduction}

Globally, renal cell carcinoma accounts for $2 \%$ of all neoplasms in adults. In 2019, 74,000 new cases of renal carcinoma were diagnosed according to the surveillance, epidemiology, and end results (SEER) statistics report accounting for 4.2\%-double universal average-of all cancer diagnoses $[1,2]$.

About thirty percent of the patients diagnosed with renal cell carcinoma have metastasis at the time of diagnosis [1]. Despite surgical resection, more than $20-50 \%$ will progress to metastatic disease [3]. The lung (70\%), lymph nodes (55\%), bone (42\%), liver (41\%), adrenal gland (15\%), and central nervous system (11\%) represent the most common sites of metastasis $[4,5]$. Breast metastasis from extramammary primary tumors is extremely rare and ranges from $0.5 \%$ to $2 \%[6,7]$. Melanoma, lymphoma, and leukemia are the most common primary tumors with metastasis to the breast [8]. In the literature, there are limited reports of metastases from renal carcinoma in the breast. In almost half of these cases, metastasis was the first sign [8]. Breast secondaries mimic breast carcinoma in clinical examination, though the diagnosis of extramammary metastasis is vital to avoid unnecessary mastectomy [9].

We present a rare case of primary renal carcinoma metastasis to the breast 3 years after nephrectomy. This is the first case to be reported from Northern Ireland.

\section{Case Report}

A 73-year-old woman presented with persistent mid and lower abdominal pain. She is known to have IBS, and blood investigations showed iron deficiency anemia. At the time of presentation, the patient had no relevant history of medical comorbidities nor history of smoking; National Early Warning Score (NEWS) was 1 (blood tests outlined in Table 1). She was referred for abdominopelvic ultrasonography which revealed left renal mass around $18 \mathrm{~cm}$ with a mixed solid and cystic component; also, hypoechoic foci were noted within the pancreas (Figures 1 and 2).

Subsequent chest CT and CT urogram were done and confirmed a large left renal mass of $18 \mathrm{~cm} \times 10 \mathrm{~cm} \times 12 \mathrm{~cm}$ with central necrosis and peripheral hypervascularity (Figure 3). The left renal vein was patent. The adrenal gland looked separable from the mass. Multiple hypervascular foci were noted within the pancreas. Small lung nodules were also noted. Multidisciplinary team (MDT) decision was for cytoreductive nephrectomy and to consider systemic therapy.

A month later, the patient had an open left nephrectomy. Renal cell carcinoma, clear cell type grade II, with no lymphovascular invasion was evident in pathological assessment; surgical margins were clear; and the tumor was classified as grade II pT3a clear cell renal cancer with evident renal vein 
TABLE 1: Blood test parameters at the time of presentation.

\begin{tabular}{|c|c|c|c|c|c|}
\hline Haemoglobin estimation & $98^{*}$ & $775-745(\mathrm{~g} / \mathrm{L})$ & Sodium & 137 & $136-145(\mathrm{mmol} / \mathrm{L})$ \\
\hline Hct & $0.313^{*}$ & $0.37-0.47$ & Potassium & 4.3 & $3.5-5.3(\mathrm{mmol} / \mathrm{L})$ \\
\hline Red blood cell (RBC) count & $3.64^{*}$ & $3.8-5.8(\mathrm{e} 12 / \mathrm{L})$ & \multirow{2}{*}{ Chloride } & \multirow{2}{*}{104} & \multirow{2}{*}{ 95-108 (mmol/L) } \\
\hline Mean corpuscular volume (MCV) & 86.0 & 76-96 (fL) & & & \\
\hline Mean corpusc. haemoglobin $(\mathrm{MCH})$ & $26.9^{*}$ & $27-32(\mathrm{pg})$ & $\mathrm{CO}_{2}$ & 25 & $22-29(\mathrm{mmol} / \mathrm{L})$ \\
\hline Mean corpusc. Hb. conc. (MCHC) & 313 & $300-350(\mathrm{~g} / \mathrm{L})$ & Urea & 4.2 & $2.5-7.8(\mathrm{mmol} / \mathrm{L})$ \\
\hline Red blood cell distribution width & $16.3^{*}$ & 9.0-15.5 & Creatinine & 78 & 45-84 $(\mu \mathrm{mol} / \mathrm{L})$ \\
\hline Platelet count & 280 & $150-440(\mathrm{e} 9 / \mathrm{L})$ & Calcium & 2.10 & $2.10-2.60(\mathrm{mmol} / \mathrm{L})$ \\
\hline Pct & - & $(\%)$ & Magnesium & 0.84 & $0.7-1.0(\mathrm{mmol} / \mathrm{L})$ \\
\hline Mean platelet volume & 9.2 & \multirow[t]{2}{*}{$(\mathrm{fL})$} & Albumin & $31^{*}$ & $35-50(\mathrm{~g} / \mathrm{L})$ \\
\hline Platelet distribution width & 9.8 & & Phosphate & 1.24 & $0.8-1.5(\mathrm{mmol} / \mathrm{L})$ \\
\hline Total white cell count & 9.0 & $4.0-11.0(\mathrm{e} 9 / \mathrm{L})$ & ALT & 23 & $<33(\mathrm{U} / \mathrm{L})$ \\
\hline Percentage lymphocytes & 16.2 & $(\%)$ & AST & 17 & $<32(\mathrm{U} / \mathrm{L})$ \\
\hline Percentage monocytes & 12.7 & $(\%)$ & GGT & $90^{*}$ & $6-42(\mathrm{U} / \mathrm{L})$ \\
\hline Percentage granulocytes & - & $(\%)$ & ALP & 15 & $30-130(\mathrm{U} / \mathrm{L})$ \\
\hline $\mathrm{LY}^{\#}$ & 1.46 & $1.0-4.8(\mathrm{e} 9 / \mathrm{L})$ & T. bilirubin & 3 & $<21(\mu \mathrm{mol} / \mathrm{L})$ \\
\hline Monocyte count & $1.15^{*}$ & 0-0.8 (e9/L) & LDH (IFCC) & 151 & $\S$ \\
\hline $\mathrm{GR}^{\#}$ & - & $(\mathrm{e} 9 / \mathrm{L})$ & Adjusted calcium & 2.32 & $2.20-2.60(\mathrm{mmol} / \mathrm{L})$ \\
\hline Percentage neutrophils & 69.6 & $(\%)$ & eGFR & $>60$ & $\left(\mathrm{~mL} / \mathrm{min} / 1.73 \mathrm{~m}^{2}\right)$ \\
\hline Percentage eosinophils & 0.7 & $(\%)$ & Serum iron level & $9^{*}$ & $13-30(\mu \mathrm{mol} / \mathrm{L})$ \\
\hline Percentage basophils & 0.8 & (\%) & Serum transferrin & $1.5^{*}$ & $1.8-3.8(\mathrm{~g} / \mathrm{L})$ \\
\hline Neutrophil count & 6.29 & 1.8-7.7 (e9/L) & Serum ferritin & $402^{*}$ & $13-300(\mu \mathrm{g} / \mathrm{L})$ \\
\hline Eosinophil count & 0.06 & $0-0.60(\mathrm{e} 9 / \mathrm{L})$ & & & \\
\hline Basophil count & 0.07 & $0-0.2(\mathrm{e} 9 / \mathrm{L})$ & Transferrin saturation index & 24 & $\$$ \\
\hline
\end{tabular}

Asterisks indicate abnormal findings.

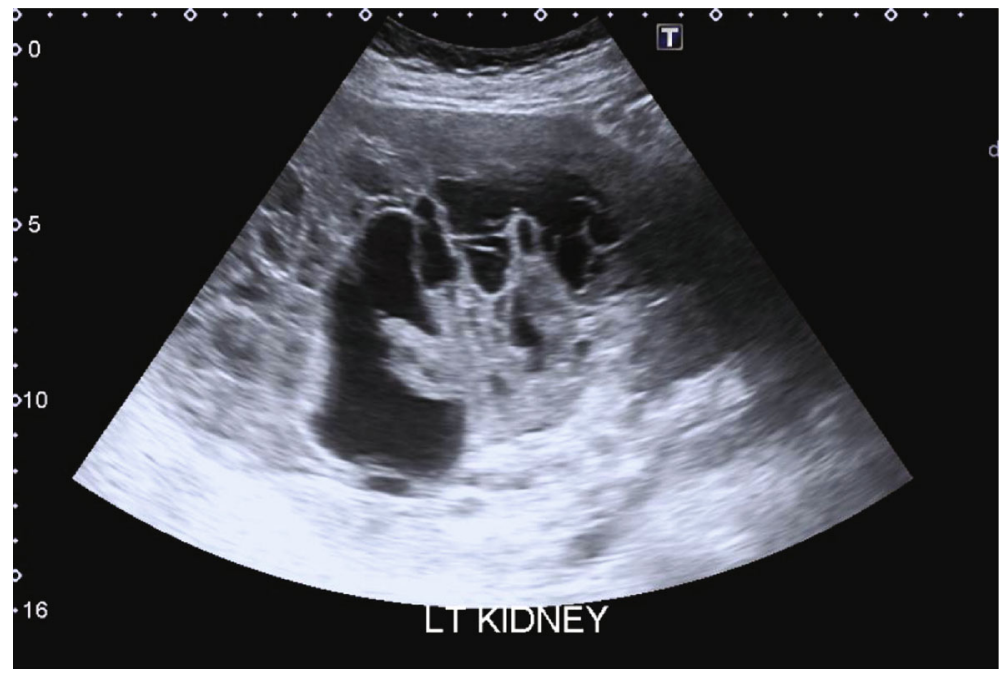

FIGURE 1: Ultrasound showing malignant looking left renal mass with mixed solid and cystic component.

involvement and no involvement of Gerota's fascia, adrenal gland, perinephric fat, or adjacent organs.

She had evidence of a small volume of metastatic disease in her preoperative imaging. Follow-up every 3 months was scheduled; interval scans in between guided by the clinical examination were done.
Initially, the patient had shown stable minimal progress of the metastatic disease for which systemic therapy was not indicated at that time. 16-month postnephrectomy, CT follow-up revealed stable chest disease with new hepatic metastasis for which she started sunitinib treatment (Figure 4). Three months later, brain CT showed brain 


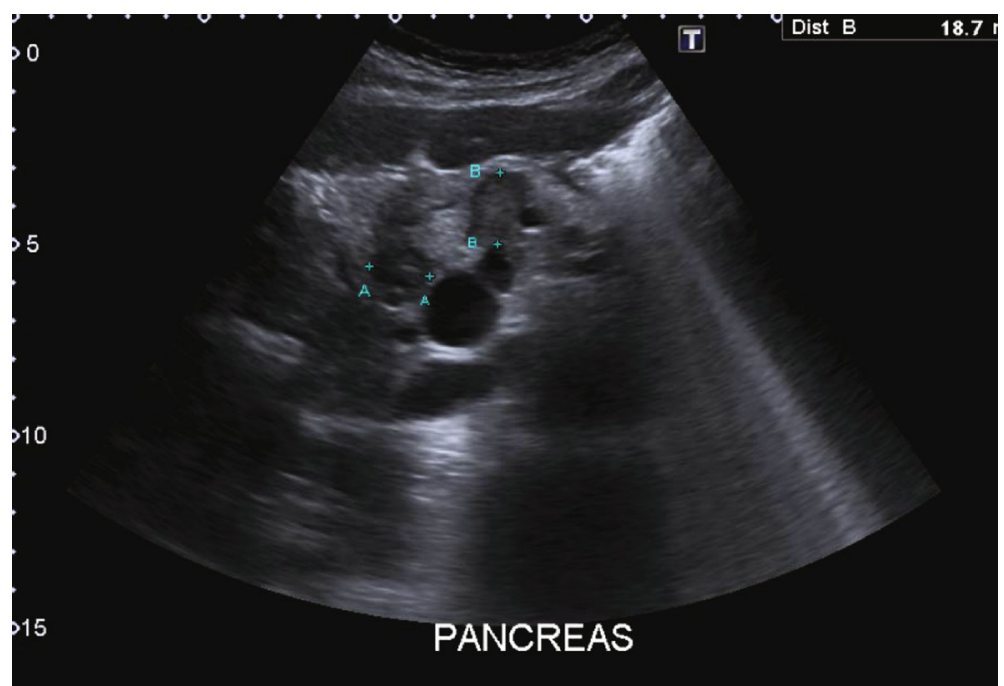

FIGURE 2: Ultrasound showing hypoechoic masses within the pancreas.

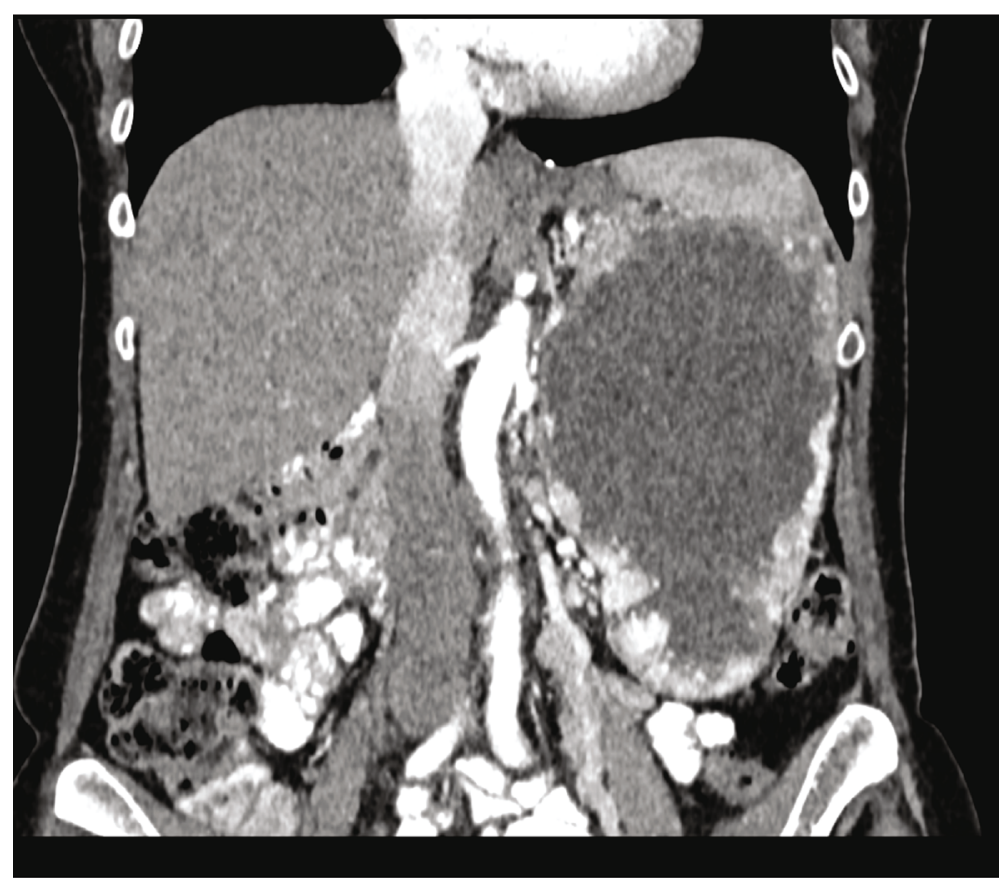

FIGURE 3: CT showing confirmed a large malignant looking left renal mass with central necrosis.

metastasis after she got an episode of confusion (Figure 5). So full head radiotherapy was started. Further progression of the metastatic disease and recurrence of the primary with new deposits in the spine were noted for which radiotherapy was indicated.

At the same time, the patient was referred on red flag breast clinic for assessment of a newly felt lump in her right breast. On examination, the lump was in the upper part of the right breast $1-2 \mathrm{~cm}$, hard, and poorly mobile with no signs of fixation to the covering skin or the underlying muscle. There was fullness in the axillae but no discrete palpable nodes. The patient stated that she had a positive family history of breast cancer.
Bilateral mammography showed a dense new mass lesion as compared to her previous mammogram done 2 years earlier (Figures 6 and 7). The mass was seen in the upper half of the right breast without microcalcifications. Since it was a new finding, M4 score was given. Breast ultrasound (US) confirmed a rather well-defined hypoechoic solid mass lesion in the right breast at 1 o'clock measuring $20 \mathrm{~mm} \times 13 \mathrm{~mm}$ with tiny cystic changes. Axilla was normal. It was reported as U5 in ultrasound. US-guided core biopsy was done in the same clinic (Figure 8).

Even though the patient had widespread RCC metastatic disease, it was important to clarify if this lesion represented a primary breast tumor which should indicate endocrine 


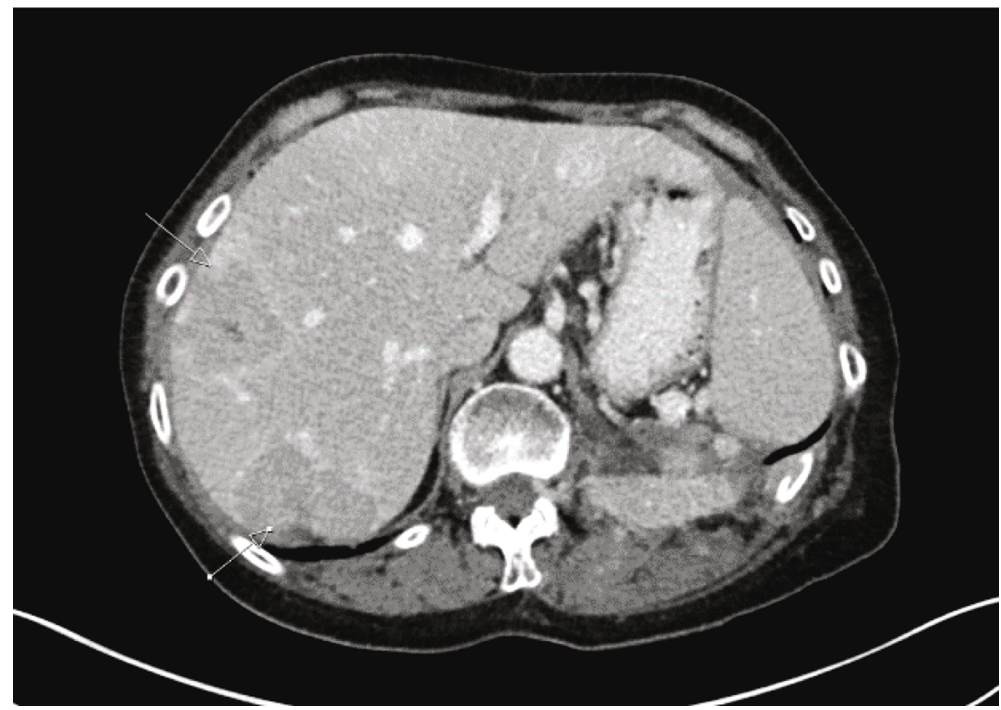

Figure 4: Follow-up CT of the abdomen showing liver deposits.

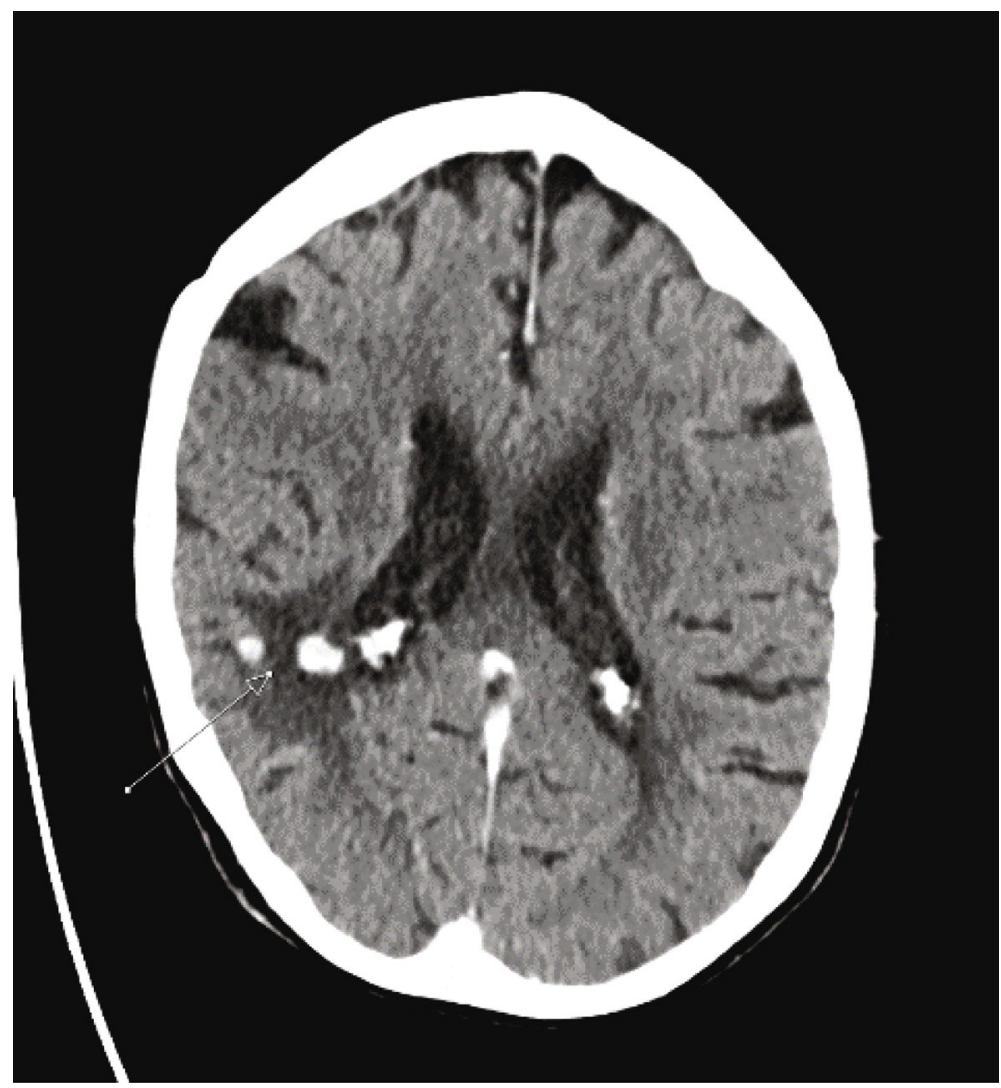

FIGURE 5: CT of the brain with contrast showing brain metastasis with surrounding edema.

therapy (if ER-positive) or a secondary from the RCC which should be managed conservatively unless getting symptomatic.

Pathology revealed breast tissue infiltrated by tumor with a nested pattern composed of clear cells. A panel of immunohistochemical markers reveals positive staining with the renal markers PAX 8 and carbonic anhydrase (Figures 9-11). CK7 is negative as are the breast markers GATA 3 and mamma- globin. Given the clinical history, the features were those of metastatic renal cell carcinoma.

\section{Discussion}

The breast is considered a rare site for metastatic lesions with reported incidence up to $2 \%$ and $6.6 \%$ in autopsy series of all malignant neoplasms $[6,9,10]$. It is primarily a female 


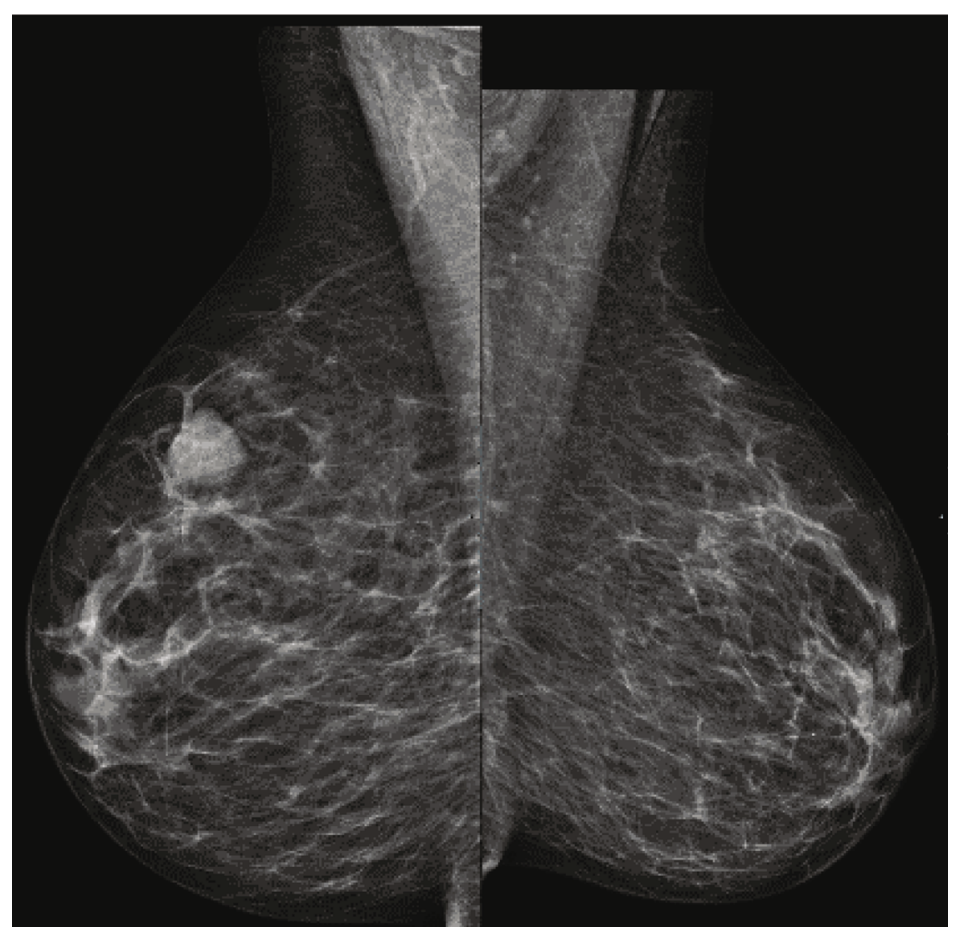

(a)

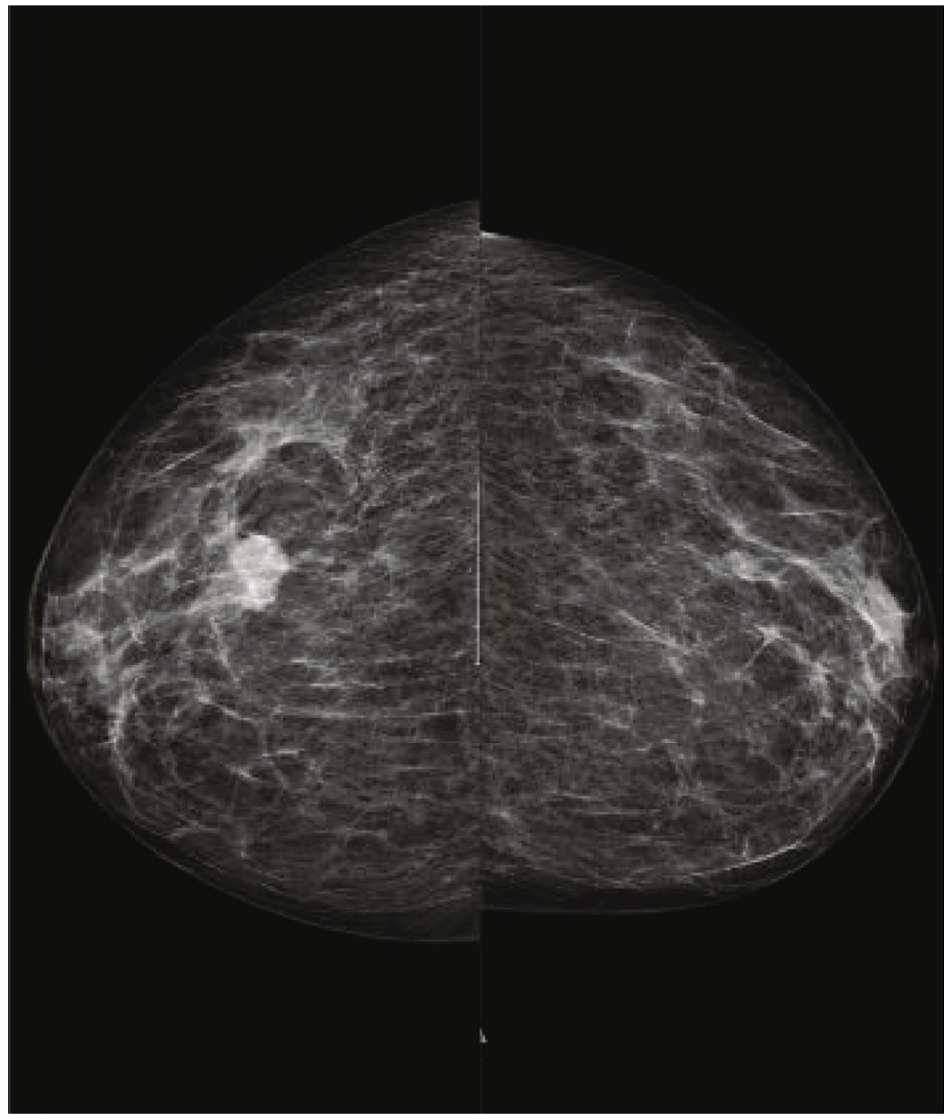

(b)

FiguRE 6: (a) Bilateral mammogram MLO view showing rounded density in the upper part of the right breast. (b) Mammogram in CC view showing a rounded right breast dense lesion. 


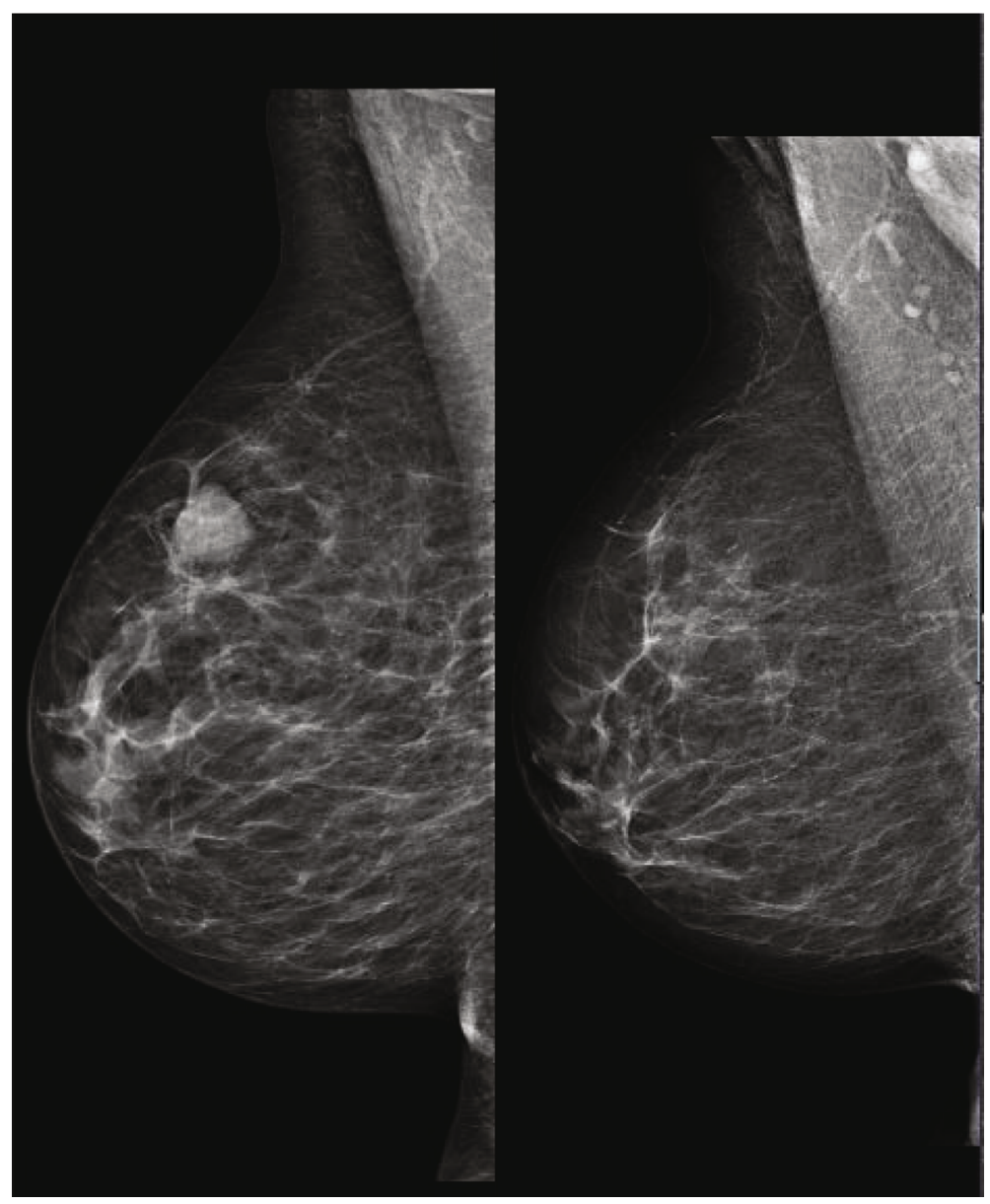

FiguRE 7: New lesion as compared to previous mammogram.

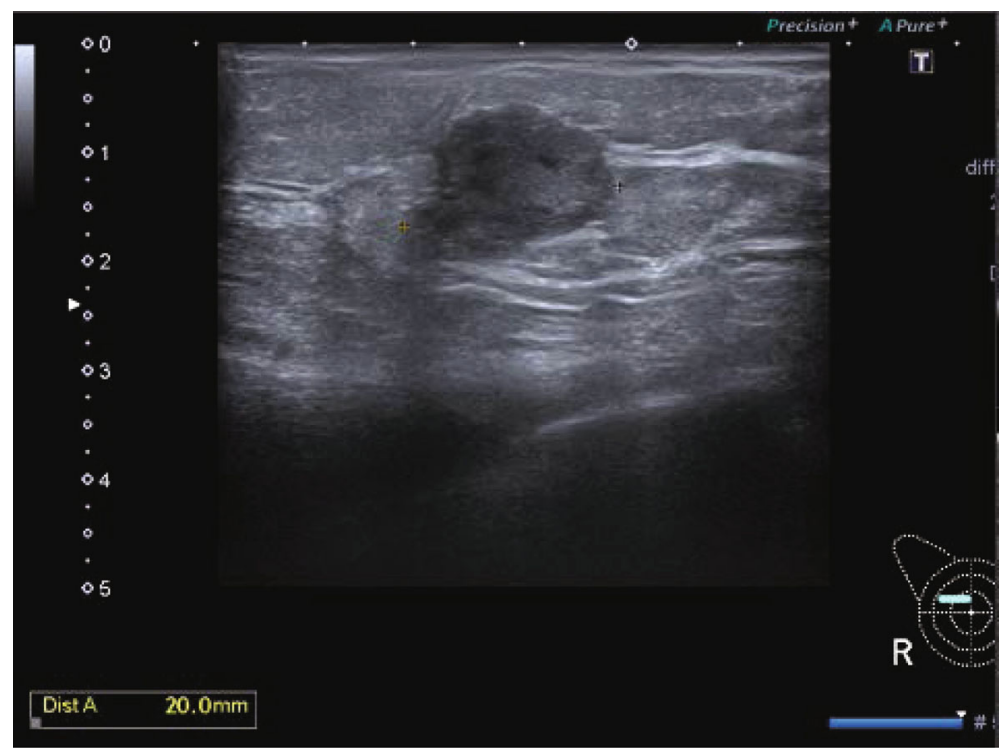

FIGURE 8: US showing a hypoechoic solid mass lesion in the right breast at 1 o'clock. 


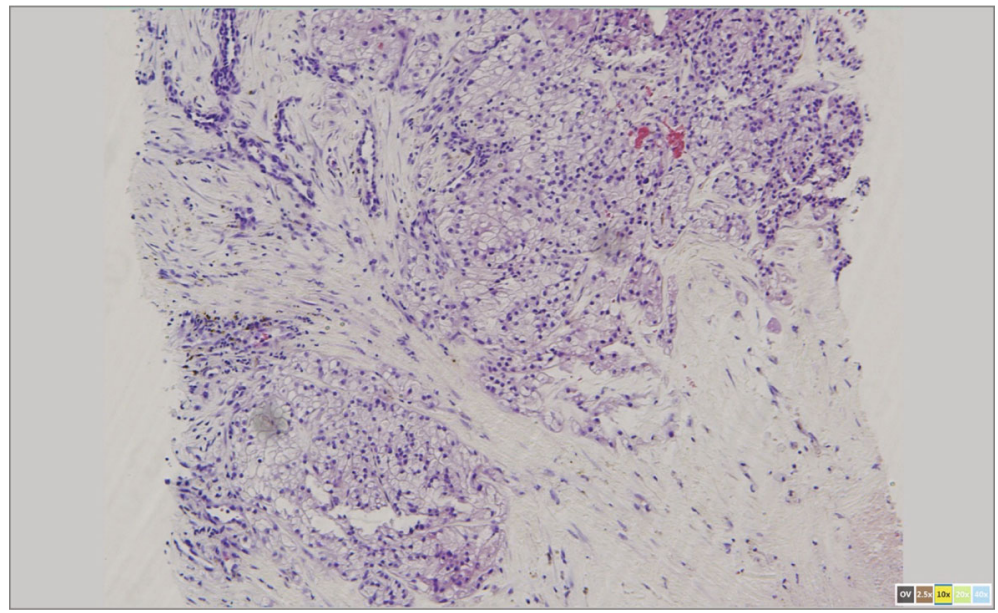

FIgURE 9: The standard H\&E-stained section showing cells with small nuclei and abundant clear cytoplasm typical of clear cell RCC.

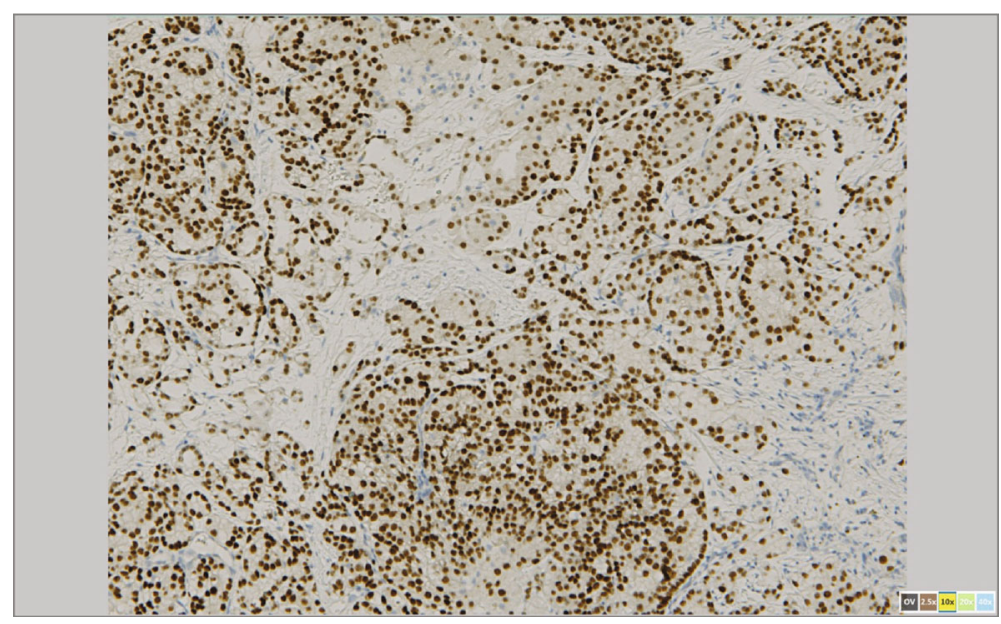

FIGURE 10: Image shows positive immunohistochemical cell nucleus staining with PAX8.

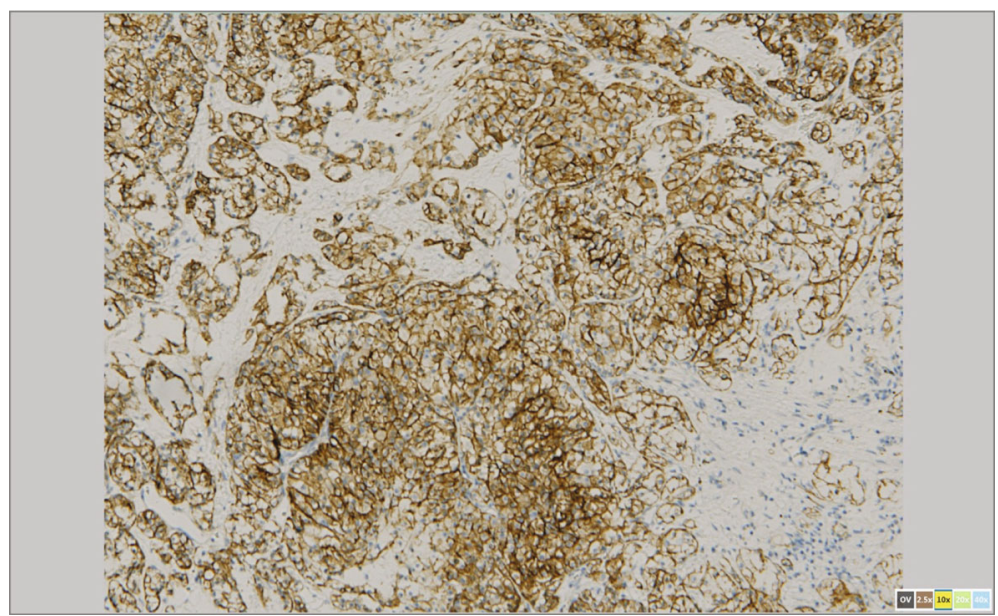

FIGURE 11: Image shows positive cell membrane staining with carbonic anhydrase. 
condition, close to that associated with primary breast cancer [11]. The most frequent metastases to the breast are from malignant melanoma, lymphoma, lung cancer, and, in men, prostatic cancer $[9,12]$. In the literature, there is scanty evidence of the prognosis in these patients who has metastatic disease in the breast [13]. However, proper differentiation between primary breast neoplasms and metastatic breast disease is essential to establish an appropriate management plan.

Approximately $25 \%-30 \%$ of patients with RCC will present with metastatic disease at the time of diagnosis. Despite that the lung, bone, regional lymph nodes, liver, and brain are the most common sites of metastases [14], renal cell carcinoma is able to metastasize in unusual organs such as the thyroid, pancreas, spleen, or vagina either individually or in the form of multimetastatic disease [15-18]. Micrometastases formation and subsequent colonization require complex adaptations by tumor cells to various host components [19]. "Seed and Soil" theory represents the ability of RCC metastasis to unusual organs [15]. Metastases to the breast from RCC are rare. The first reported RCC metastasis to the breast was in the early 4th decade of the twentieth century, and only 25 cases have been reported in the literature [14].

Smoking is a major risk factor for cancer process including growth and metastasis. Both particulate and gas carcinogens act on the cell cycle, oncogene, or antioncogene loosening in addition to cell death process alteration with resultant abnormal cell growth and tumor invasiveness [20]. A large retrospective study found smoking had relative risk of 1.6-fold of RCC [1]. In this case, the patient had no history of smoking or known risk factors explaining the behaviour of disease progression.

History of extramammary tumors should be considered during evaluation of suspicious breast lesion; combined approach of clinical history, examination, and investigations is important to achieve proper diagnosis, which in turn influences proper management plan and prognosis [21]. Differentiation of primary breast cancer from secondary metastasis was vital in this patient as it was necessary to guide the management. Although primary breast malignancy is a common presentation in such age, however, the history of current metastatic disease elevated the index of suspicion.

Pathological assessment represents an integral part of the multidisciplinary approach in such situations. Their abilities to relevant immunohistochemical markers are of great importance to differentiate primary breast neoplasms from metastasis [21]. Immunohistochemical markers in this patient revealed positive staining with the renal markers PAX 8 and carbonic anhydrase and negative CK7, GATA 3, and mammaglobin.

As part of the triple assessment, the mammographic appearance of metastatic breast cancer is usually well defined with a lack of microcalcifications and a history of malignancy should increase the suspicion of metastasis $[13,14,22]$. In fact, the optimum treatment is controversial [13, 23]. Mastectomy and lymph node dissection are unnecessary because they are not a curative treatment. Palliative radiotherapy and target therapy are good local and systemic control with tolerable toxicity [13, 22, 23].

Surgical management (mastectomy and lymph node dissection) in such condition does not offer curative option; palliative options as radiotherapy and target therapy offer good and systemic and local control with endurable toxicity [9, $13,22,23]$.

In this case, surgery was only indicated in case of being symptomatic. This patient had disseminated metastasis (breast, pulmonary, liver, spine, and brain) besides the local recurrence. There were no effective therapeutic options for such disseminated disease. Based on a multidisciplinary approach, palliative care was followed.

There is minimal information in the literature regarding the prognosis of patients with metastatic disease to the breast, and further studies are warranted [9].

In conclusion, breast metastasis from RCC is very rare. Primary and secondary breast cancer may be clinical and radiological. Triple assessment (clinical, radiological, and histological evaluation) is mandatory for confirmation of the diagnosis. An individualized and multidisciplinary approach of such patients should be followed.

\section{Ethical Approval}

This article follows the ethical guidelines in accordance with the Declaration of Helsinki (1964).

\section{Conflicts of Interest}

The authors declare that they have no conflicts of interest.

\section{References}

[1] S. A. Padala, A. Barsouk, K. C. Thandra et al., "Epidemiology of renal cell carcinoma," World Journal of Oncology, vol. 11, no. 3, pp. 79-87, 2020.

[2] N. Howlander, A. M. Noone, and M. Krapcho, SEER cancer statistics review 1975-2016, National Cancer Institute, 2019.

[3] S. C. Campbell and B. R. Lane, Malignant renal tumors, Campbell-Walsh Urol, 2012.

[4] D. L. Wahner-Roedler and T. J. Sebo, "Renal cell carcinoma: diagnosis based on metastatic manifestations," Mayo Clinic Proceedings, vol. 72, no. 10, pp. 935-941, 1997.

[5] H. M. Tarraza Jr., S. E. Meltzer, M. DeCain, and M. A. Jones, "Vaginal metastases from renal cell carcinoma: report of four cases and review of the literature," European Journal of Gynaecological Oncology, vol. 19, no. 1, pp. 14-18, 1998.

[6] S. I. Hajdu and J. A. Urban, "Cancers metastatic to the breast," Cancer, vol. 29, no. 6, pp. 1691-1696, 1972.

[7] L. Vassalli, V. D. Ferrari, E. Simoncini et al., "Solitary breast metastases from a renal cell carcinoma," Breast Cancer Research and Treatment, vol. 68, no. 1, pp. 29-31, 2001.

[8] S. A. McLauglin, D. D. Thiel, S. L. Smith, M. J. Wehle, and D. M. Menke, "Solitary breast mass as initial presentation of clinically silent metastatic renal cell carcinoma," Breast, vol. 15, no. 3, pp. 427-429, 2006.

[9] M. Mahrous, W. Al Morsy, A. Al-Hujaily, and S. Al-Sulimani, "Breast metastasis from renal cell carcinoma: rare initial 
presentation of disease recurrence after 5 years," Journal of Breast Cancer, vol. 15, no. 2, pp. 244-247, 2012.

[10] S. Pagano, F. Franzoso, and P. Ruggeri, "Renal cell carcinoma metastases. Review of unusual clinical metastases, metastatic modes and patterns and comparison between clinical and autopsy metastatic series," Scandinavian Journal of Urology and Nephrology, vol. 30, no. 3, pp. 165-172, 1996.

[11] B. Vergier, M. Trojani, I. de Mascarel, J. M. Coindre, and A. Le Treut, "Metastases to the breast: differential diagnosis from primary breast carcinoma," Journal of Surgical Oncology, vol. 48, no. 2, pp. 112-116, 1991.

[12] A. Forte, M. I. Peronace, L. S. Gallinaro et al., "Metastasis to the breast of a renal carcinoma: a clinical case," European Review for Medical and Pharmacological Sciences, vol. 3, no. 3, pp. 115-118, 1999.

[13] A. Alzaraa, A. Vodovnik, H. Montgomery, M. Saeed, and N. Sharma, "Breast metastasis from a renal cell cancer," World Journal of Surgical Oncology, vol. 5, no. 1, p. 25, 2007.

[14] G. Falco, F. Buggi, P. A. Sanna, A. Dubini, and S. Folli, "Breast metastases from a renal cell carcinoma. A case report and review of the literature," International Journal of Surgery Case Reports, vol. 5, no. 4, pp. 193-195, 2014.

[15] F. Sellner, "Isolated pancreatic metastases of renal cell carcinoma-a paradigm of a seed and soil mechanism: a literature analysis of 1,034 observations," Frontiers in Oncology, vol. 10, p. 709, 2020.

[16] A. R. Jimenez, M. D. M. Rivera Rolon, E. Eyzaguirre, and C. Clement, "Vaginal bleeding as initial presentation of an aggressive renal cell carcinoma: a case report and review of the literature," Case Reports in Pathology, vol. 2018, Article ID 2109279, 4 pages, 2018.

[17] M. Costantini, G. Tuderti, F. Minisola et al., "Metachronous isolated splenic metastasis in a young patient with renal cell carcinoma: case report and literature review," Urology, vol. 127, pp. 13-18, 2019.

[18] T. R. Geisbush, Z. Dymon, M. S. Gabriel, and V. Yedavalli, “A multimodal and pathological analysis of a renal cell carcinoma metastasis to the thyroid gland 11 years post nephrectomy," Journal of Radiology Case Reports, vol. 13, no. 4, pp. 1-9, 2019.

[19] T. Shibue and R. A. Weinberg, "Metastatic colonization: settlement, adaptation and propagation of tumor cells in a foreign tissue environment," Seminars in Cancer Biology, vol. 21, no. 2, pp. 99-106, 2011, Epub 2010 Dec 9.

[20] A. Pezzuto, F. Citarella, I. Croghan, and G. Tonini, “The effects of cigarette smoking extracts on cell cycle and tumor spread: novel evidence," Future Science $O A$, vol. 5, no. 5, article FSO394, 2019.

[21] K. Pesce, M. J. Chico, J. S. Delgado, A. C. Z. Sierra, C. Hadad, and A. Wernicke, "Metastases to the breast, an uncommon diagnosis: what do radiologists need to know?," Radiología, vol. 61, no. 4, pp. 324-332, 2019.

[22] W. K. Lee, J. N. Cawson, P. A. Hill, J. Hoang, and H. Rouse, "Renal cell carcinoma metastasis to the breast: mammographic, sonographic, CT, and pathologic correlation," The Breast Journal, vol. 13, no. 3, pp. 316-317, 2007.

[23] A. Vaughan, J. R. Dietz, J. F. Moley et al., "Metastatic disease to the breast: the Washington University experience," World Journal of Surgical Oncology, vol. 5, no. 1, p. 74, 2007. 